\title{
Article \\ Influence of Fins Number and Frosting on Heat Transfer through Longitudinal Finned Tubes of LNG Ambient Air Vaporizers
}

\author{
Filip Lisowski ${ }^{1, *(1)}$ and Edward Lisowski ${ }^{2}$ \\ 1 Department of Machine Design and Composite Structures, Cracow University of Technology, \\ ul. Warszawska 24, 31-155 Cracow, Poland \\ 2 Department of Applied Informatics, Cracow University of Technology, ul. Warszawska 24, \\ 31-155 Cracow, Poland; edward.lisowski@pk.edu.pl \\ * Correspondence: filip.lisowski@pk.edu.pl
}

check for

updates

Citation: Lisowski, F.; Lisowski, E. Influence of Fins Number and Frosting on Heat Transfer through Longitudinal Finned Tubes of LNG Ambient Air Vaporizers. Energies 2022, 15, 280. https://doi.org/ $10.3390 /$ en15010280

Academic Editors: Paweł Ocłoń and Francisco P. Brito

Received: 20 October 2021

Accepted: 8 December 2021

Published: 1 January 2022

Publisher's Note: MDPI stays neutral with regard to jurisdictional claims in published maps and institutional affiliations.

Copyright: (C) 2022 by the authors. Licensee MDPI, Basel, Switzerland. This article is an open access article distributed under the terms and conditions of the Creative Commons Attribution (CC BY) license (https:// creativecommons.org/licenses/by/ $4.0 /)$.

\begin{abstract}
The use of cryogenic liquefied gasses in industry is constantly increasing both for process purposes and for power supply needs. The liquefied natural gas (LNG) is stored at cryogenic temperature and its immediate use in gaseous form requires its evaporation. The heat needed to cause a phase change is usually delivered by means of vaporizers. This paper presents a numerical analysis of the influence of the fins number and frost accumulated within the fins surface on the heat transferred through the aluminum finned tubes of LNG ambient air vaporizers. The calculations were carried out applying finite element thermal analysis within Ansys software as well as using an analytical approach. As a result, the heat rate per unit length of the finned tube was obtained. The results were compared for different numbers of longitudinal fins both without frost and for total frosting of the tubes.
\end{abstract}

Keywords: ambient air vaporizers; longitudinal finned tubes; liquefied natural gas; frosting

\section{Introduction}

Natural gas in liquid form is commonly known as LNG. It has a number of advantages and its use continues to increase both for stationary and mobile applications. Liquefied natural gas is stored at a low temperature under pressure. Small and medium storage tanks of double-wall construction are insulated by vacuum and highly efficient cryogenic insulations [1]. A system of internal supports is also necessary to limit the heat leakage into the tank [2]. For the direct use of natural gas there is usually a need to obtain a gaseous phase. This is achieved by providing an appropriate amount of heat. The heat in LNG regasification stations is delivered by means of vaporizers. The most popular are ambient air vaporizers with longitudinal finned tubes. Such vaporizers have the form of a block, the height of which depends on the length of finned tubes, while the transverse dimensions are determined by the number of tubes in rows and the distance between them. Aluminum alloys are the basic materials in the construction of finned tubes, due to their high thermal conductivity and the possibility of extruding fins of relatively large dimensions. Vaporizers are designed for a wide range of applications, both mobile and stationary. Finned tubes can be arranged either vertically or horizontally. Therefore, in addition to offering sufficient evaporation efficiency, the vaporizers must meet the appropriate strength requirements. While designing their construction, an impact of climate including wind actions, seismic forces and the accumulation of frost should be taken into account. Due to the frost formation, the mechanical load on the finned tubes increases, the space between them decreases and the vaporizer efficiency is significantly reduced. For ambient air vaporizers installed outdoors, it is difficult to determine the exact theoretical relations describing the operating parameters due to the variable working conditions depending on climate. Problems related to the design and operation of longitudinal finned tube vaporizers have been of interest to the authors of several publications and patents. The authors of publication [3] proposed 
the analytical model of the frost formation for a one-dimensional problem. A relation between air humidity and temperature of a cold flat surface as well as a relation between air velocity and thickness of a frost layer were determined. In the paper [4], the results of numerical and experimental analyses, including the correlation between the thickness of the frost layer, temperature inside the tube, an angle between fins and their thickness, were presented. The selected relations of the above parameters were proposed for optimal design of vaporizers. The coupled dynamic model of frost formation and flow boiling heat transfer of LNG was presented in paper [5]. One of the main conclusions of the above study was that the thermal resistance of the frost layer increased with the operation time and is the major factor affecting the temperature of finned tube walls. In the paper [6], the results of an experimental study on frost formation within the finned tubes array were reported. Based on visual observations during the frost formation, it was found that if the part of the fin surface had temperature above the freezing point but still below the dew point, the moist air condensed on the upper part of the fin while frost was formed nearby the fin base. As a result, the thickness of the frost at the base of the fins was greater than at the tip. Another approach to determine the operating parameters of vaporizers was to use finite element analysis and computational fluid dynamics (CFD) software. In the paper [7], the numerical modeling of the laminar free convection of air around a horizontal cylinder with external longitudinal fins was presented. It was concluded that using a greater number of fins with shorter lengths resulted in better heat transfer. The authors of paper [8] presented simulation results of convective heat transfer related to a horizontal finned tube. A new treatment of the boundary conditions on the outer side of the finned tube was proposed. The obtained relative errors of the average Nusselt number of the laminar natural convection were less than $0.5 \%$ in comparison to the reference solutions. It was also shown that for a specific number of fins, there was an optimum fin height which provided maximum heat transfer. CFD analysis results of the ambient air vaporizer finned tube of the one meter length were presented by the authors of paper [9]. The ambient air was considered to be dry and the nitrogen was accepted as a cryogenic liquid. As a result, the relationship of the Rayleigh number and the Nusselt number was obtained, which was proportional within a certain range. In the paper [10], the CFD analysis was involved in order to verify the experimental results concerning heat transfer through the outer surface of longitudinal finned tube made of aluminum. The analysis referred to the distribution of heat transfer coefficients on the pipe perimeter and along the pipe. In the study [11], the methodology of determining optimal geometric parameters of longitudinal finned tubes with wavy fins was presented. The tubes belonged to the outdoor heat pump evaporator operating under wind induced air flow. Thermal calculations were performed by modeling a mixed convection process applying finite volume method within Ansys Fluent CFD software. The authors of paper [12] analyzed the heat transfer between ambient air and LNG under supercritical pressure conditions. Heat transfer performance of AVV and optimal fin configurations were investigated applying CFD modeling. The author of paper [13] presented the application of CFD analysis to predict the condition of fog cloud formation, and dispersion around the array consisted of six ambient air vaporizers.

Taking into account the modern construction of ambient air vaporizers and current technological capabilities, various types of tube profiles are used in their construction. Typical solutions are based on the use of longitudinal finned tubes. In general, theoretical analyses show that the greater the fin radius and the higher the number of fins, the higher the efficiency of the vaporizer. However, the number of fins is limited due to the small amount of space around the central pipe perimeter. Excessive increases in the fin radius also result in a loss of stability due to external influences such as wind loads. There were several patented solutions for stiffening the fins and improving the efficiency of cryogenic vaporizers. Due to the vaporizer efficiency improvement, the configurations of arrays including the tubes with various number of fins were presented in the patent [14]. The author of patent [15] described the structure of the ambient air vaporizer with longitudinally finned tubes, which had rails on their fins designed for assembling them with the use of 
channel brackets, which significantly prevented the rotation of tubes. The inner surface of the tube was additionally notched to increase the heat transfer area. The author of patent [16] proposed to place a solid rod with a predetermined length within the central opening of the tube in order to increase the rate of heat transfer between the cryogenic fluid in its vapor phase and the ambient air.

The purpose of this paper was the use of finite element thermal analysis to determine the heat rate per unit length of the longitudinal finned tubes and compare how it decreased due to frost formation. An impact of the fins number and frosting was considered in the analysis. For the case of frosting, the most unfavorable conditions of operation were accepted for calculations. It was assumed that heat is transferred to the finned tubes by natural convection and the tubes were entirely covered by frost. Numerical solution was verified by means of convergence tests. In turn, for the case of no frosting, the numerical analysis was additionally verified with an analytical approach.

\section{Object of Study}

Six cross-sections of longitudinal finned tubes differing in the number of fins around the perimeter were accepted for analysis as shown in Figure 1.

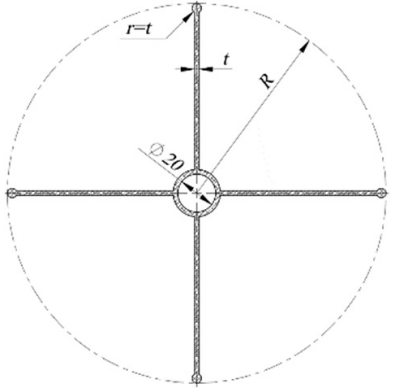

(a)

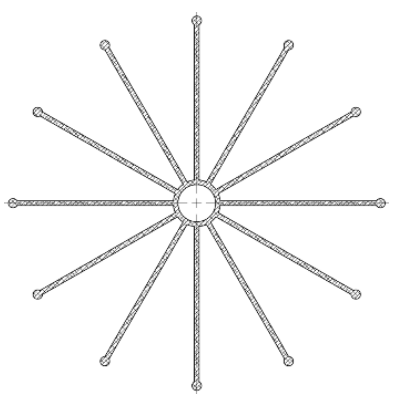

(d)

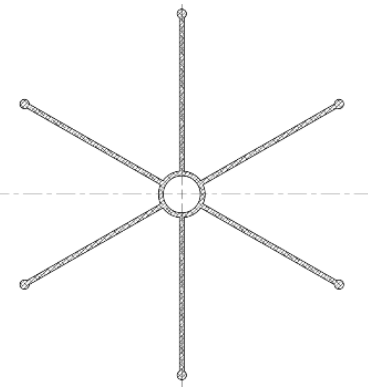

(b)

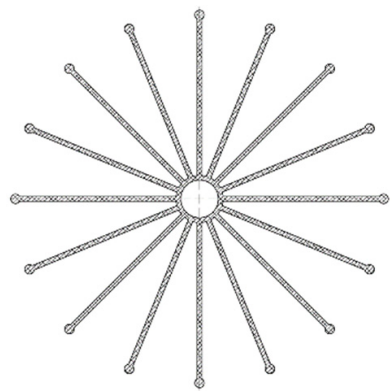

(e)

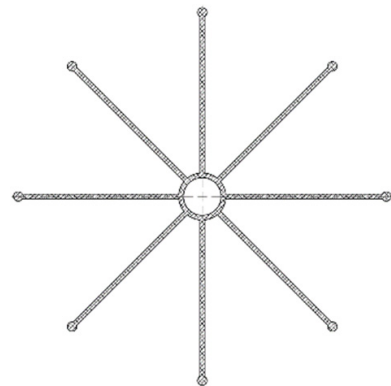

(c)

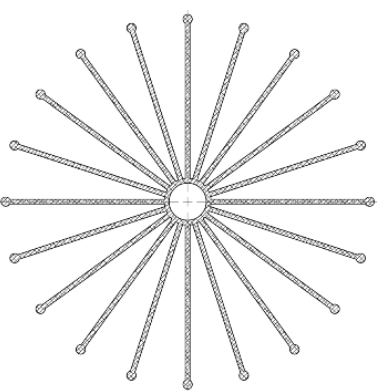

(f)

Figure 1. Cross-sections of tubes $(t=2.5 \mathrm{~mm}, R=100 \mathrm{~mm}$ ) with: (a) 4 fins; (b) 6 fins; (c) 8 fins; (d) 12 fins; (e) 16 fins; (f) 20 fins.

The number of fins $n$, outer radius $R$ and fin thickness $t$ were taken as $n=\{4,6,8,12,16$, $20\}, R=\{50,75,100,125,150\} \mathrm{mm}$ and $t=\{1.5,2.0,2.5,3.0,3.5\} \mathrm{mm}$ resulting in 150 different geometry variations. Because of the relatively large height of the fins with respect to their thickness, all fins had cylindrical stiffening rails at the tips of the fins with radius $r=t$.

Longitudinal finned tubes of ambient air vaporizers are placed at specific distances from each other. This distance provides a space for the airflow, but also is a space where the frost is accumulated. Figure 2 shows the finned tubes during vaporizer operation. The tubes in the first row are entirely covered by frost. The layer of frost which covers the tube can have an irregular outline of the outer surface. For the purpose of the analysis in this study, it was assumed that the sections of tubes under consideration were completely covered by frost with the cylindrical outer surfaces as shown in Figure 3. 


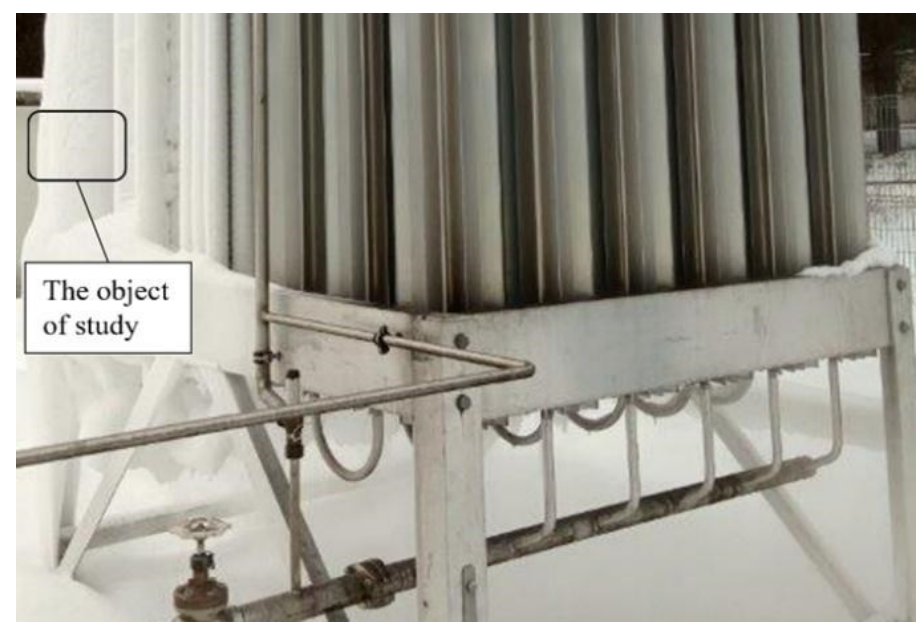

Figure 2. Finned tubes of LNG ambient air vaporizer totally covered by frost.

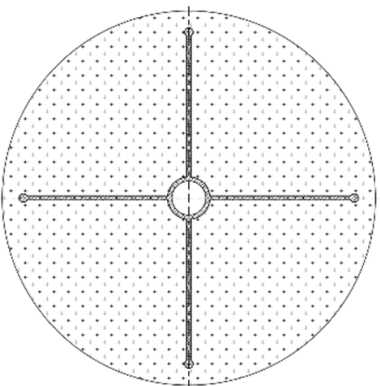

(a)

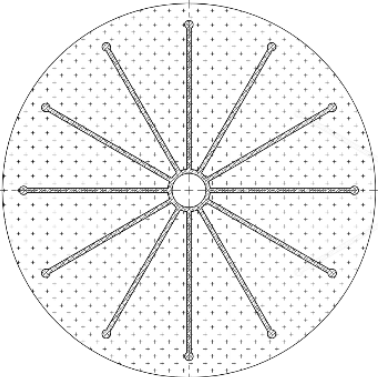

(d)

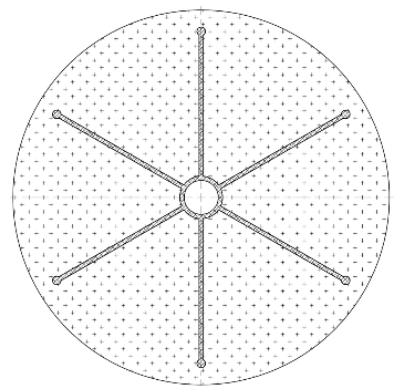

(b)

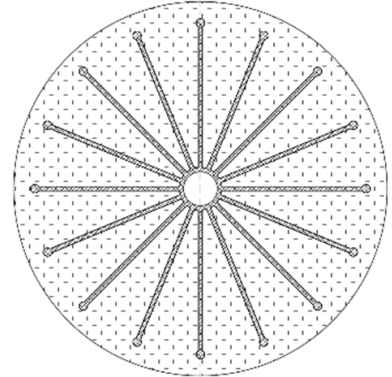

(e)

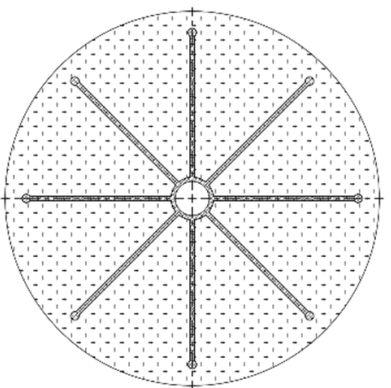

(c)

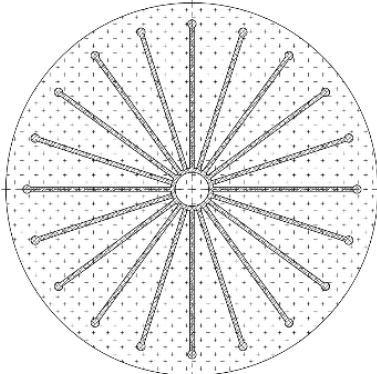

(f)

Figure 3. Cross-sections of the tubes ( $t=2.5 \mathrm{~mm}, R=100 \mathrm{~mm}$ ) with: (a) 4 fins; (b) 6 fins; (c) 8 fins; (d) 12 fins; (e) 16 fins; (f) 20 fins entirely covered by frost.

\section{Heat Transfer through Finned Tubes}

The heat transferred through the finned tube without frosting can be estimated using an analytical approach [17]. Heat transferred through the outer surface of the finned tube from the ambient air at temperature $T_{o}$ to the liquid at temperature $T_{i}$ can be calculated using Equation (1), where $T_{o}>T_{i}$. Both the heat transferred by the fins surfaces and the heat transferred by the surfaces between the fins are taken into account.

$$
Q=h_{o} A_{o}\left(T_{o}-T_{i}\right)
$$

where: $Q$-heat [W], $h_{0}$ - heat transfer coefficient related to the outer surface of the tube $\left[\mathrm{W} /\left(\mathrm{m}^{2} \mathrm{~K}\right)\right], A_{o}$-outer surface area of the tube without fins $\left[\mathrm{m}^{2}\right]$.

Figure 4 presents an auxiliary diagram for determining the heat transfer coefficient related to the outer surface of the tube. 


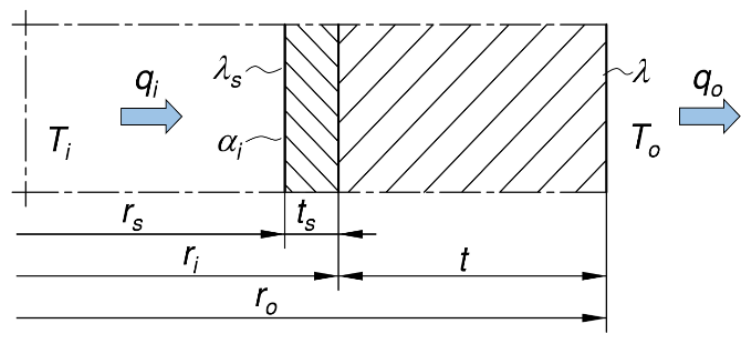

Figure 4. Diagram for determining the heat transfer coefficient.

The heat transfer coefficient $h_{0}$ related to the outer surface of the tube without fins is calculated considering that the temperature drop $\left(T_{o}-T_{i}\right)$ include four temperature drops:

- $\quad$ Temperature drop related to the temperature of the medium $T_{i}$ and the temperature of the inner surface of the sediment $T_{S}$ :

$$
T_{i}-\left.T\right|_{r=r_{s}}=\frac{\dot{q}_{s}}{\alpha_{i}}
$$

- $\quad$ Because for a circular tube there are relations as given by Equations (3) and (4), the temperature drop from Equation (2) takes the form indicated in Equation (5).

$$
\begin{gathered}
Q=\dot{q}_{s} 2 \pi r_{s} H=\dot{q}_{i} 2 \pi r_{i} H=\dot{q}_{o} 2 \pi r_{o} H \\
\dot{q}_{s} r_{s}=\dot{q}_{i} r_{i}=\dot{q}_{o} r_{o} \\
T_{i}-\left.T_{s}\right|_{r=r_{s}}=\frac{\dot{q}_{o} r_{o}}{r_{i} \alpha_{i}}
\end{gathered}
$$

where: $\dot{q}_{s}$-heat flux density at the sediment layer $\left[\mathrm{W} / \mathrm{m}^{2}\right], \dot{q}_{i}$ - heat flux density at the inner surface of the tube $\left[\mathrm{W} / \mathrm{m}^{2}\right], \dot{q}_{0}$-heat flux density at the outer surface of the tube $\left[\mathrm{W} / \mathrm{m}^{2}\right], H$-tube length $[\mathrm{m}], r_{s}$-inner radius of the sediment layer $[\mathrm{m}], r_{i}$-inner radius of the tube $[\mathrm{m}], r_{0}$ - outer radius of the tube $[\mathrm{m}], \alpha_{i}$-heat transfer coefficient at the inner surface of the tube $\left[\mathrm{W} /\left(\mathrm{m}^{2} \mathrm{~K}\right)\right]$.

- Temperature drop in the sediment layer:

$$
\begin{aligned}
\left.T\right|_{r=r_{s}}-\left.T\right|_{r=r_{i}} \approx \frac{\dot{q}_{s} t_{s}}{\alpha_{i}} \approx \frac{\dot{q}_{o} r_{o}}{r_{i}} \frac{t_{s}}{\lambda_{s}} \\
R_{s}=\frac{t_{s}}{\lambda_{s}}
\end{aligned}
$$

where: $R_{s}$-thermal resistance of sediment $\left[\left(\mathrm{m}^{2} \mathrm{~K}\right) / \mathrm{W}\right], t_{s}$-thickness of the sediment layer $[\mathrm{mm}], \lambda_{s}$-thermal conductivity of the sediment $[\mathrm{W} /(\mathrm{mK})]$.

Considering Equation (7) in Equation (6), the temperature drop in the sediment layer is:

$$
\left.T\right|_{r=r_{s}}-\left.T\right|_{r=r_{i}}=\frac{\dot{q}_{o} r_{o}}{r_{i}} R_{S}
$$

- Temperature drop across the wall thickness of the tube:

$$
\left.T\right|_{r=r_{i}}-\left.T\right|_{r=r_{o}}=\frac{\dot{q}_{o} r_{o}}{\lambda} \ln \frac{r_{o}}{r_{i}}
$$

where: $\lambda$-thermal conductivity $[\mathrm{W} /(\mathrm{mK})]$. 
- Temperature drop between the outer surface of the tube and the ambient air is:

$$
\left.T\right|_{r=r_{i}}-T_{o}=\frac{\dot{q}_{o}}{\alpha_{r}}
$$

where: $\alpha_{r}$-reduced heat transfer coefficient $\left[\mathrm{W} /\left(\mathrm{m}^{2} \mathrm{~K}\right)\right]$.

After adding the temperature drops, given by Equations (5) and (8)-(10) the temperature drop $\left(T_{i}-T_{o}\right)$ is obtained as follows:

$$
T_{i}-T_{o}=\frac{\dot{q}_{o} r_{o}}{r_{i} \alpha_{i}}+\frac{\dot{q}_{o} r_{o}}{r_{i}} R_{s}+\frac{\dot{q}_{o} r_{o}}{\lambda} \ln \frac{r_{o}}{r_{i}}+\frac{\dot{q}_{o}}{\alpha_{r}}
$$

From the definition of the heat transfer coefficient it follows that:

$$
T_{i}-T_{o}=\frac{\dot{q}_{o}}{h_{o}}
$$

From Equations (11) and (12) results that:

$$
\frac{\dot{q}_{o}}{h_{o}}=\frac{\dot{q}_{o} r_{o}}{r_{i} \alpha_{i}}+\frac{\dot{q}_{o} r_{o}}{r_{i}} R_{s}+\frac{\dot{q}_{o} r_{o}}{\lambda} \ln \frac{r_{o}}{r_{i}}+\frac{\dot{q}_{o}}{\alpha_{r}}
$$

Hence, the heat transfer coefficient $h_{0}$ related to the outer surface of the tube is obtained from Equation (14) as follows:

$$
\frac{1}{h_{0}}=\frac{r_{o}}{r_{i}} \frac{1}{\alpha_{i}}+\frac{r_{o}}{r_{i}} R_{s}+\frac{r_{o}}{\lambda} \ln \frac{r_{o}}{r_{i}}+\frac{1}{\alpha_{r}}
$$

The reduced heat transfer coefficient $\alpha_{r}$ and the efficiency of the fin $\eta_{f}$ can be calculated using Equations (15) and (16).

$$
\begin{gathered}
\alpha_{r}=\alpha_{o}\left(\frac{A_{b f}}{A_{o}}+\frac{A_{f}}{A_{o}} \eta_{f}\right) \\
\eta_{f}=\frac{\tanh \left(m L_{c}\right)}{m L_{c}}
\end{gathered}
$$

where: $A_{o}$-outer surface area of the tube $\left[\mathrm{m}^{2}\right], A_{f}$ - surface area of fins $\left[\mathrm{m}^{2}\right], A_{b f}$-surface area of tube between fins $\left[\mathrm{m}^{2}\right], L_{\mathcal{c}}$-fin height [m], $t$-fin thickness $[\mathrm{m}], \eta_{f}$ - fin efficiency.

For a constant value of thermal conductivity $\lambda$ and a constant cross-sectional area of the fin $A$, the differential equation describing the heat transfer in the fin is of the form:

$$
\frac{d^{2} T}{d x^{2}}-m\left(T-T_{o}\right)=0
$$

The fin parameter $m$ is given as follows:

$$
m^{2}=\frac{\alpha_{0} P}{\lambda A}
$$

where: $P$-fin circumference $[\mathrm{m}], A$-cross sectional area of the fin $\left[\mathrm{m}^{2}\right]$.

For a straight fin, the circuit over which the heat exchange takes place is:

$$
P=2(w+t)
$$

where: $w$-fin length [m], t-fin thickness [m]. 
Because for the cases under consideration $t<<w$, the fin parameter is in the form:

$$
m^{2}=\frac{2 \alpha_{o}(w+t)}{\lambda w t} \approx \frac{2 \alpha_{o}}{\lambda t}
$$

Finally, the fin parameter $m$ and the fin height $L_{c}$, which includes the heat transfer at the tip of the fin, are given as follows:

$$
m=\sqrt{\frac{2 \alpha_{o}}{\lambda t}}, L_{c}=L+\frac{t}{2}
$$

where: L-actual length of the fin [m].

An influence of a sediment layer collected on the inner surface of the tube can be taken into account by accepting a resistance $R_{S}$ in the calculations. In contrast, due to the complex geometry, the effect of deposits on the outer surfaces of the finned tube on the heat transfer cannot be estimated using the quoted analytical solution. In such a case, the use of finite element method can be a more practical approach, which allows the complex geometry to be taken into account in the thermal analysis. If the finned tubes are covered by a frost layer with an irregular outer surface, this can be also easily taken into account.

\section{Finite Element Analysis}

The analysis concerned the sections of longitudinal finned tubes with a length of $1 \mathrm{~m}$. All the tubes' profiles were analyzed, both without frosting as well as entirely covered by frost. A transient thermal analysis was carried out using ANSYS software. An alternative could be a steady-state thermal analysis. However, in this case, it would be necessary to experimentally determine the temperature at the outer surface of the tubes for each of the cases analyzed, and then it would be necessary to define the temperature as a boundary condition in the FEA thermal analysis. Shell elements of 8-nodes were used. The mesh accepted for analysis is shown in Figure 5 for the example of the tube with 8 fins. The mesh with the same size of elements was accepted for all calculation cases.

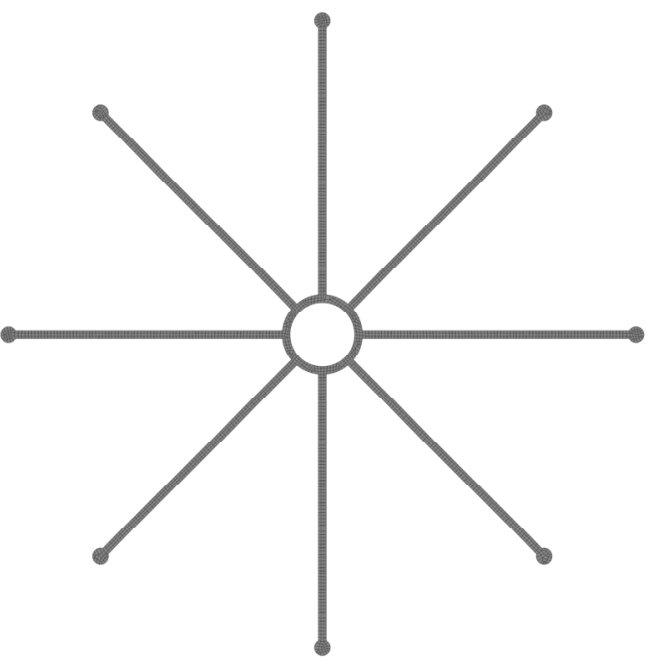

(a)

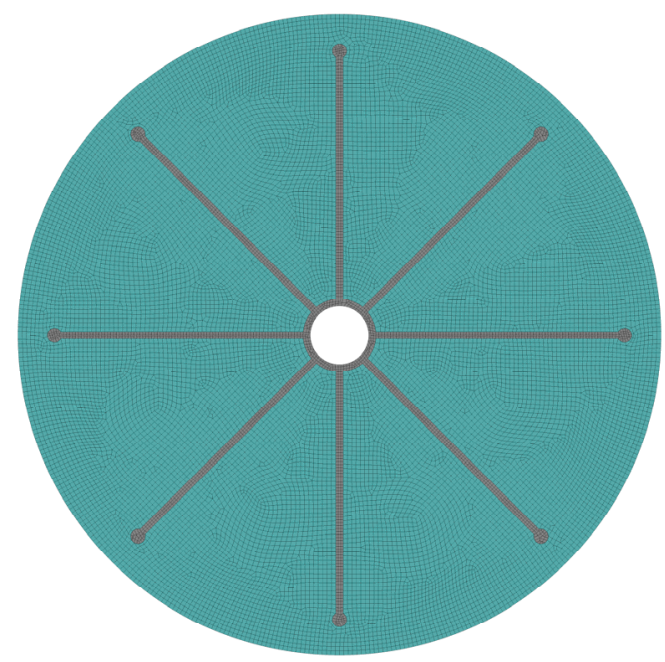

(b)

Figure 5. Mesh of the tube with 8 fins: (a) without frost, (b) entirely covered by frost.

\subsection{Assumptions for Thermal Analysis}

The following assumptions were made for finite element thermal analysis:

- The tubes were made of aluminum alloy of thermal conductivity shown in Figure 6;

- The internal surface of the central pipe had a constant temperature of $-160{ }^{\circ} \mathrm{C}$;

- The ambient temperature was equal to $20^{\circ} \mathrm{C}$; 
- The external surface of finned tube or frost layer exchanged heat with the environment by the convection with convection coefficient of $7 \mathrm{~W} /\left(\mathrm{m}^{2}{ }^{\circ} \mathrm{C}\right)$;

- The thermal conductivity coefficient of the frost was assumed to be constant with an average value equal to $0.2 \mathrm{~W} /\left(\mathrm{m}^{\circ} \mathrm{C}\right)[18]$.

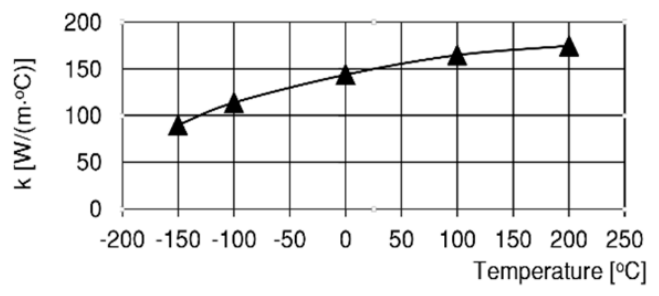

Figure 6. Thermal conductivity of aluminum alloy [19].

\subsection{Mesh Validation}

The convergence of numerical solution was tested in order to verify results obtained only by means of finite element analysis. The convergence of all obtained results arose from the mesh refinement. The convergence of the numerical solution was tested concerning total heat on the outer surface of finned tubes or on the outer surface of frost in the function of mesh refinement steps. Step zero referred to rough mesh. In each subsequent refinement step, the size of finite elements was twice as small as for the preceding step. Due to the geometric similarity of the models, convergence of the solution was tested on the example of three tube sections with number of fins $n=\{4,8,16\}$ and parameters $t=2.5 \mathrm{~mm}$ and $R=100 \mathrm{~mm}$. The results of mesh validation are shown in Figure 7. For all of the considered cases, the mesh after 6 steps of refinement was accepted as the mesh providing converged solution.
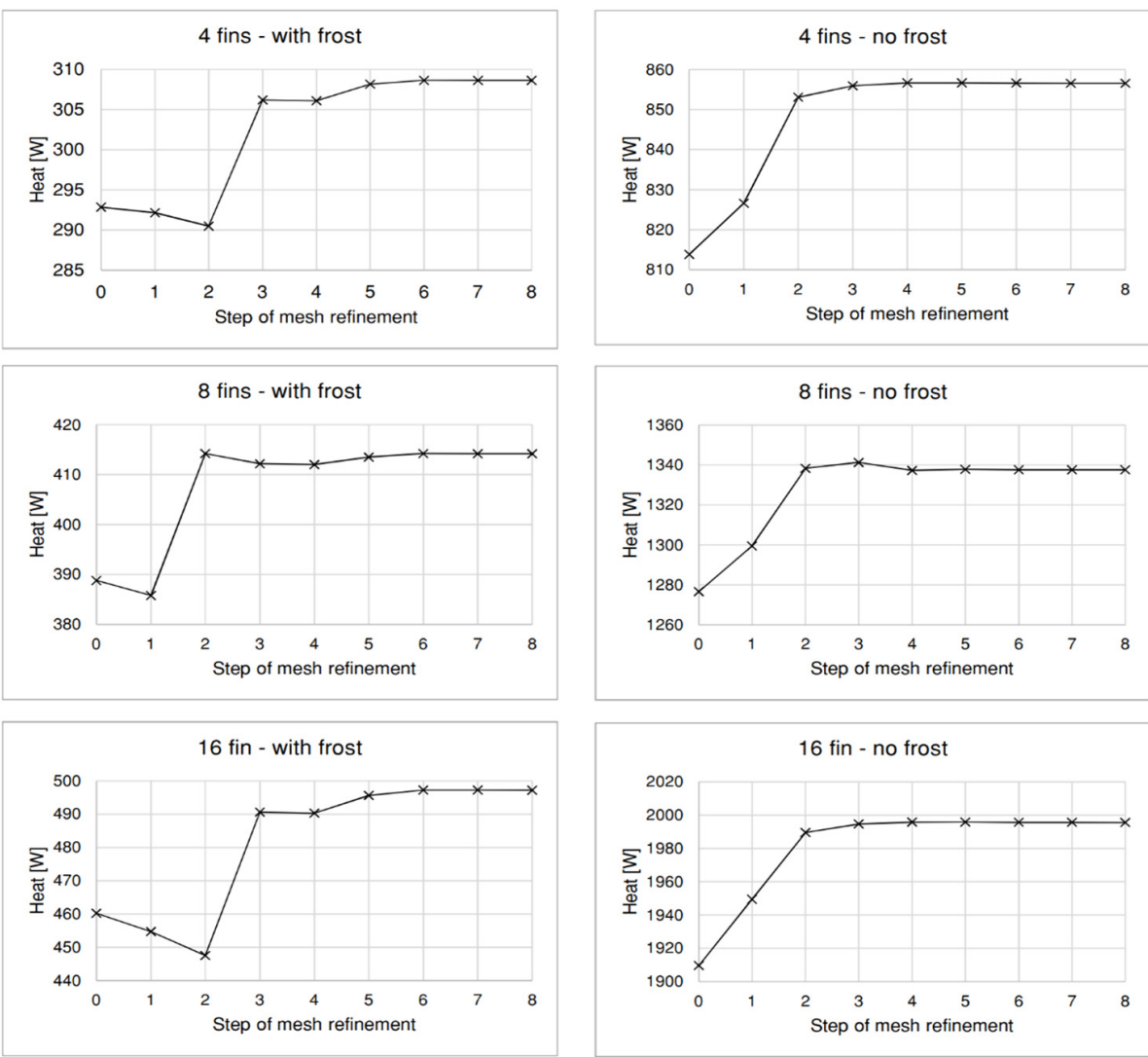

Figure 7. Total heat depending on the mesh refinement. 


\subsection{Results and Discussion}

The results of finite element thermal analysis were presented as temperature distributions as shown in Figures 8-13. The heat transferred through one meter length of finned tube and the heat decrease due to frosting were presented in the form of graphs in Figures 14-19. The graphs include analytical and FEA results for the case without frosting and FEA results for the case of total frosting of the longitudinal finned tubes. Comparing the analytical and FEA results for the case without frosting, a good conformity of the obtained values can be observed.

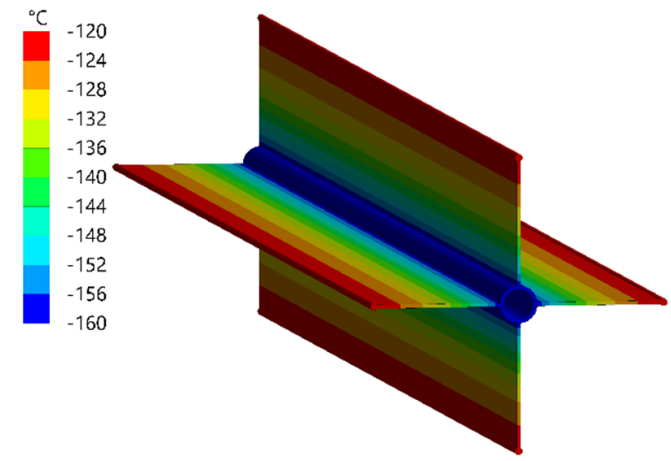

(a)

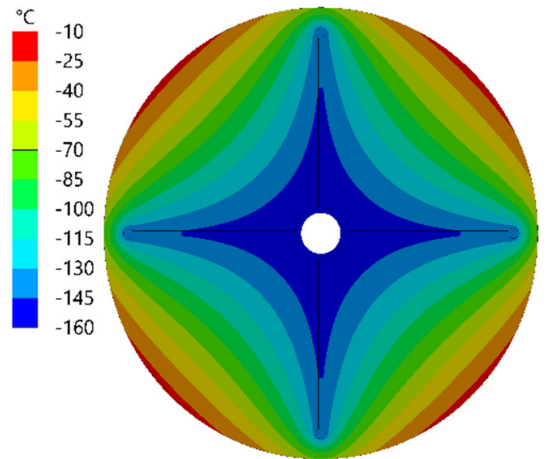

(b)

Figure 8. Temperature distribution: (a) 4 fins-no frost, (b) 4 fins with frost.

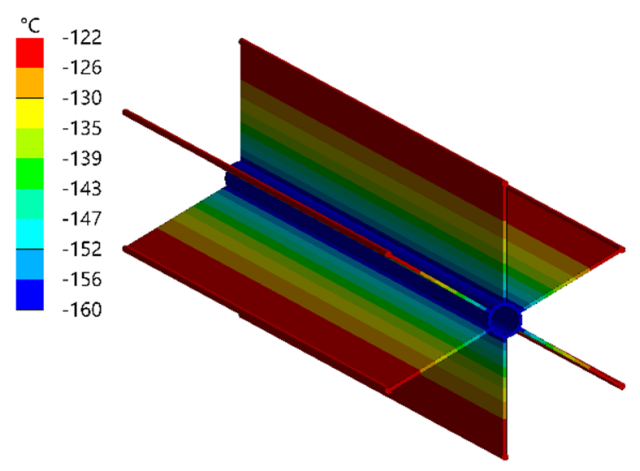

(a)

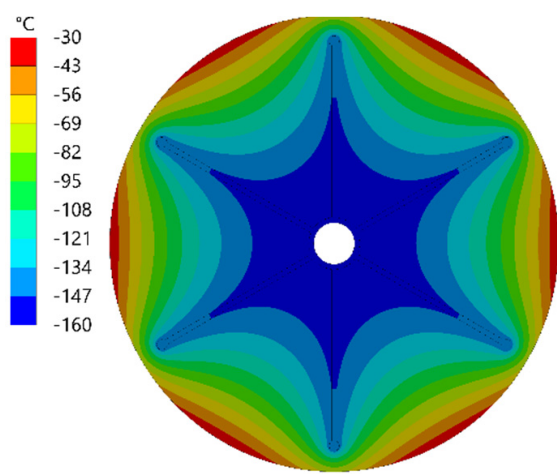

(b)

Figure 9. Temperature distribution: (a) 6 fins-no frost, (b) 6 fins with frost.

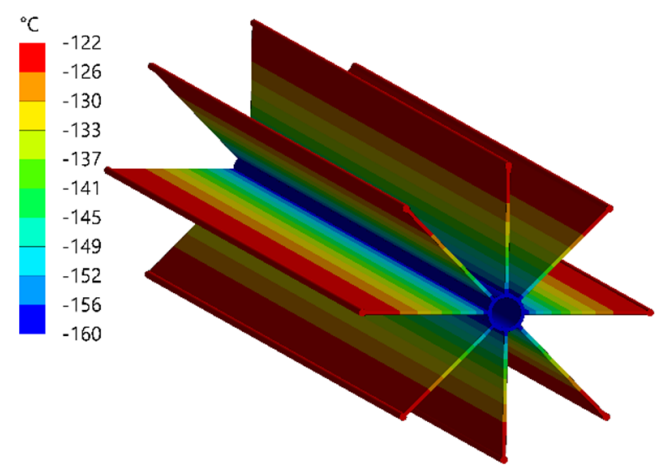

(a)

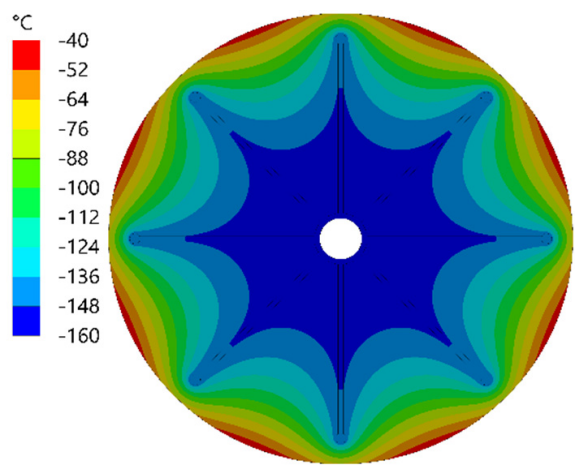

(b)

Figure 10. Temperature distribution: (a) 8 fins-no frost, (b) 8 fins with frost. 


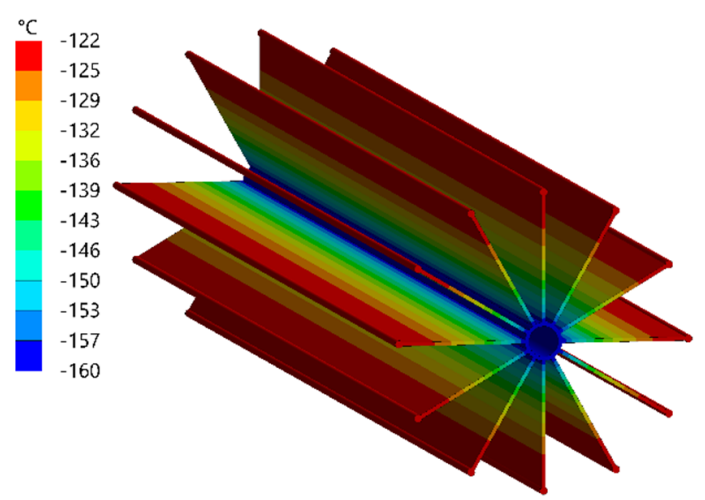

(a)

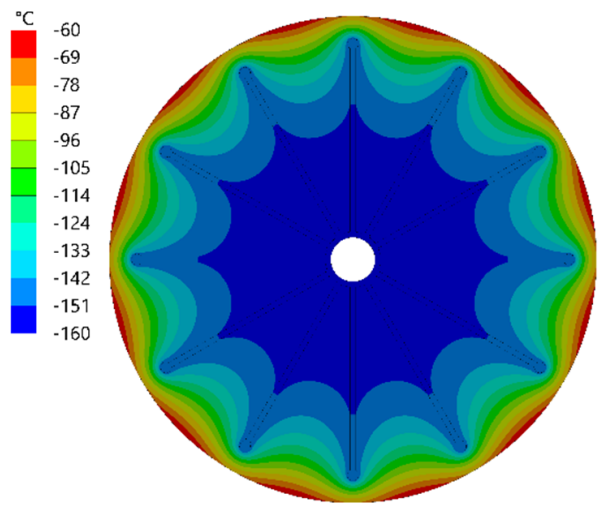

(b)

Figure 11. Temperature distribution: (a) 12 fins-no frost, (b) 12 fins with frost.

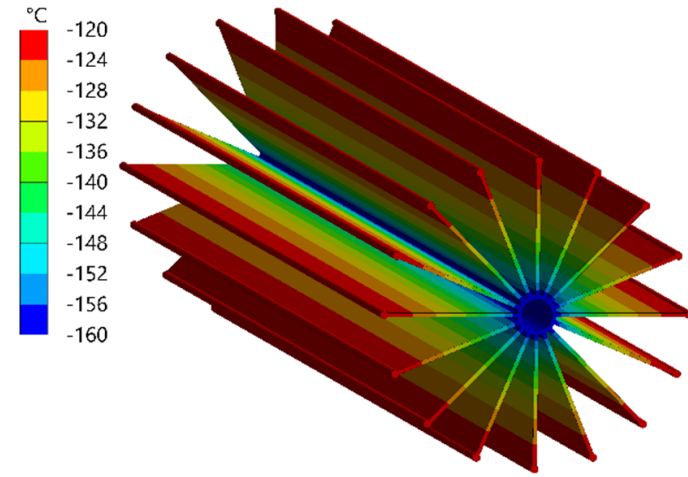

(a)

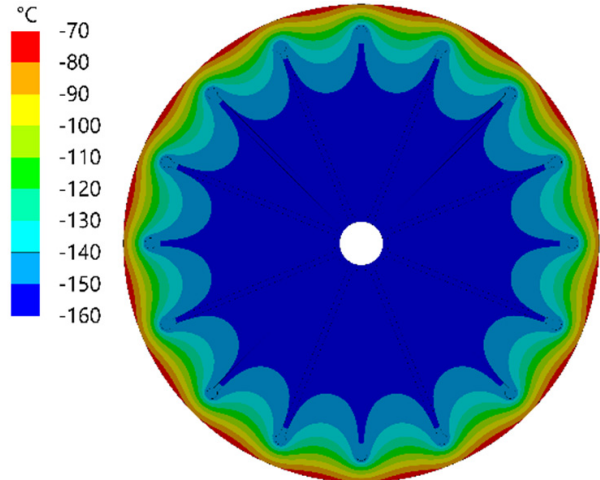

(b)

Figure 12. Temperature distribution: (a) 16 fins-no frost, (b) 16 fins with frost.

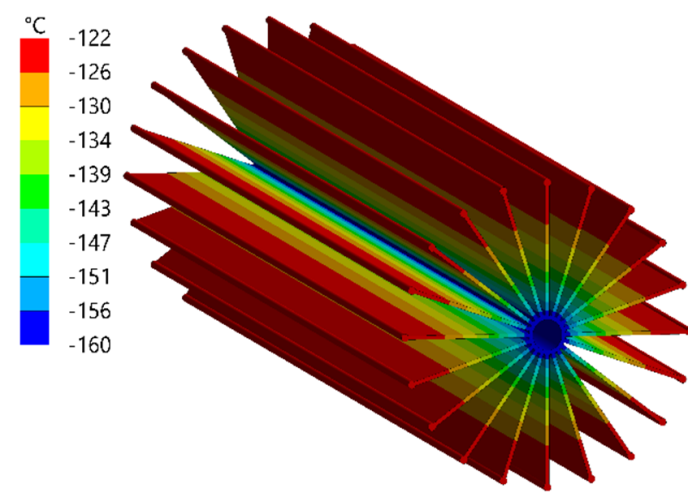

(a)

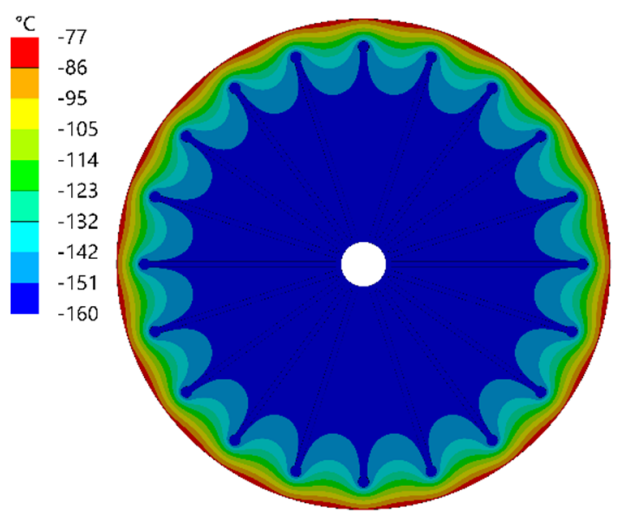

(b)

Figure 13. Temperature distribution: (a) 20 fins-no frost, (b) 20 fins with frost. 


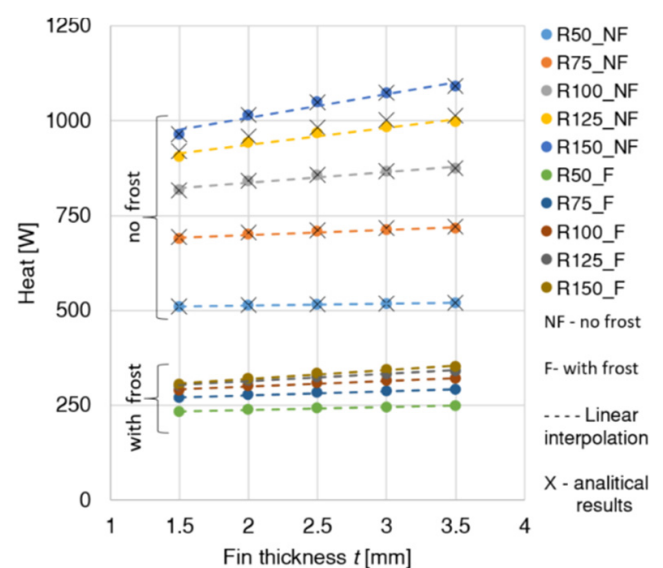

(a)

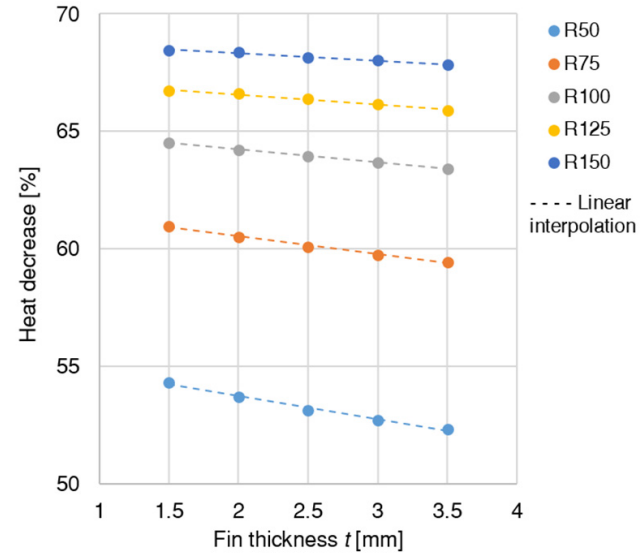

(b)

Figure 14. (a) Heat transferred through the $1 \mathrm{~m}$ length of the finned tube with 4 fins, (b) Heat decrease due to frosting.

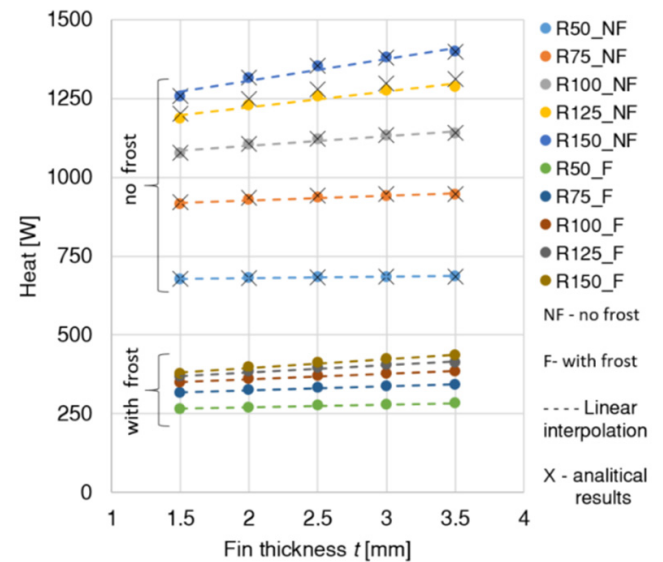

(a)

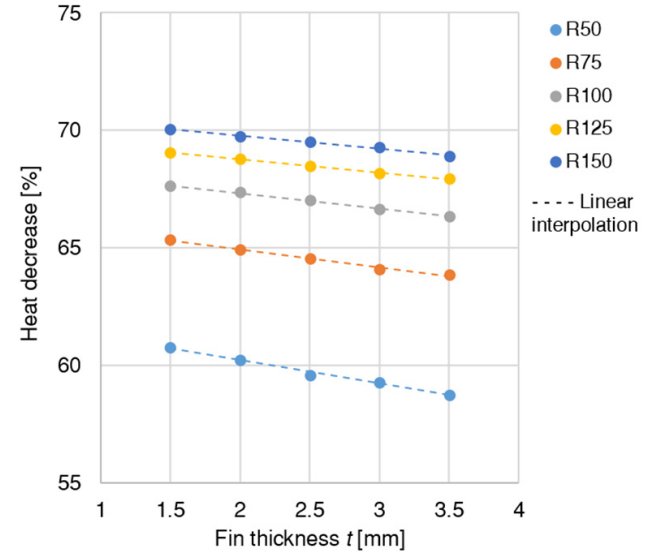

(b)

Figure 15. (a) Heat transferred through the $1 \mathrm{~m}$ length of the finned tube with 6 fins, (b) Heat decrease due to frosting.

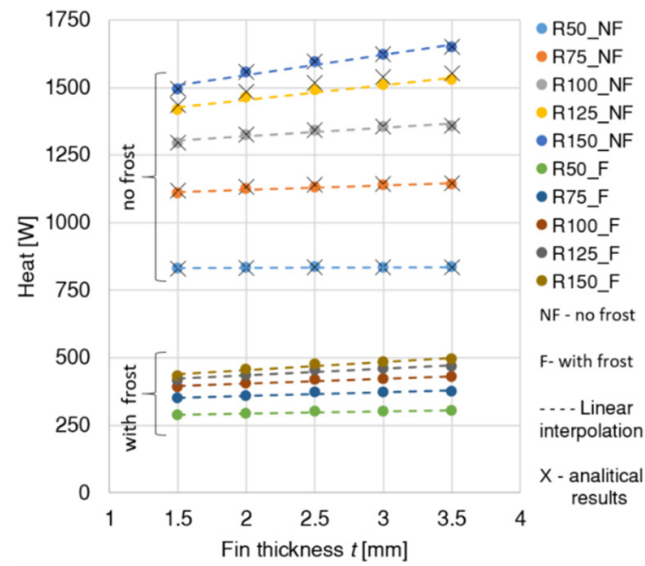

(a)

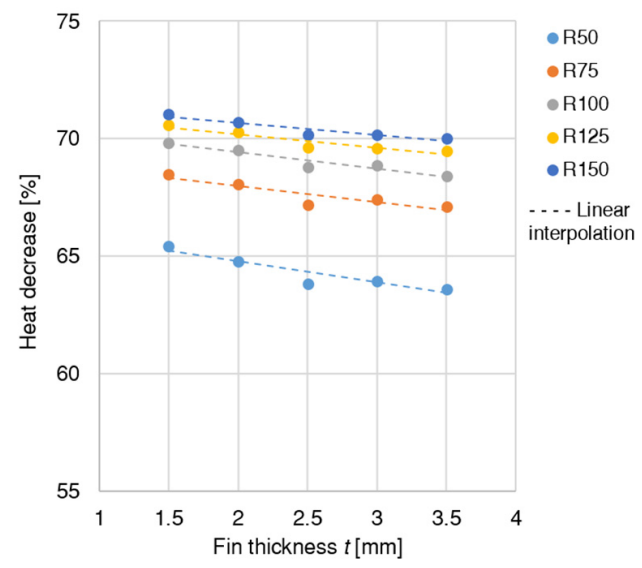

(b)

Figure 16. (a) Heat transferred through the $1 \mathrm{~m}$ length of the finned tube with 8 fins, (b) Heat decrease due to frosting. 


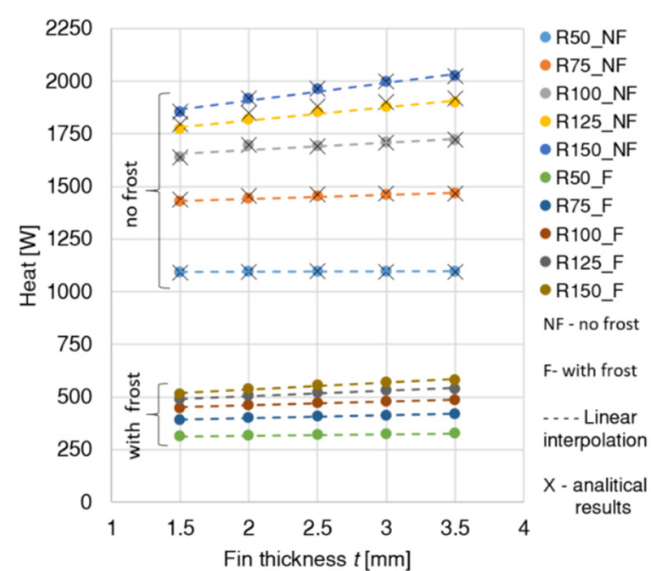

(a)

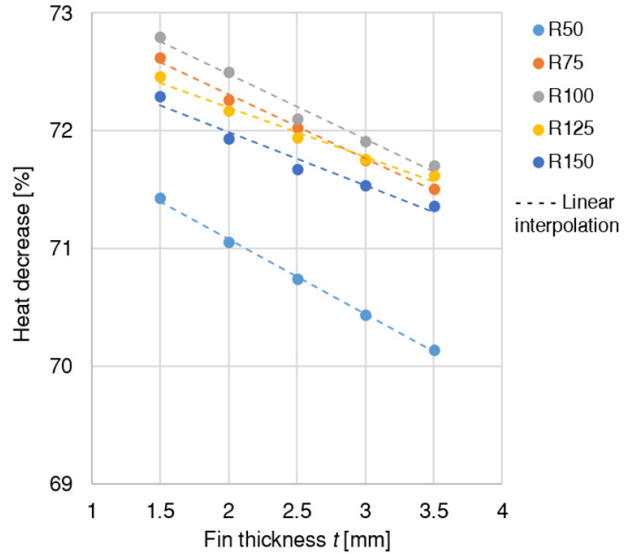

(b)

Figure 17. (a) Heat transferred through the $1 \mathrm{~m}$ length of the finned tube with 12 fins, (b) Heat decrease due to frosting.

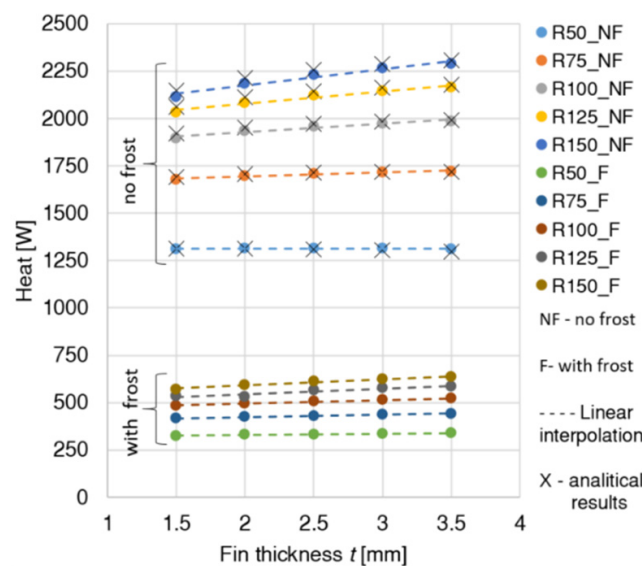

(a)

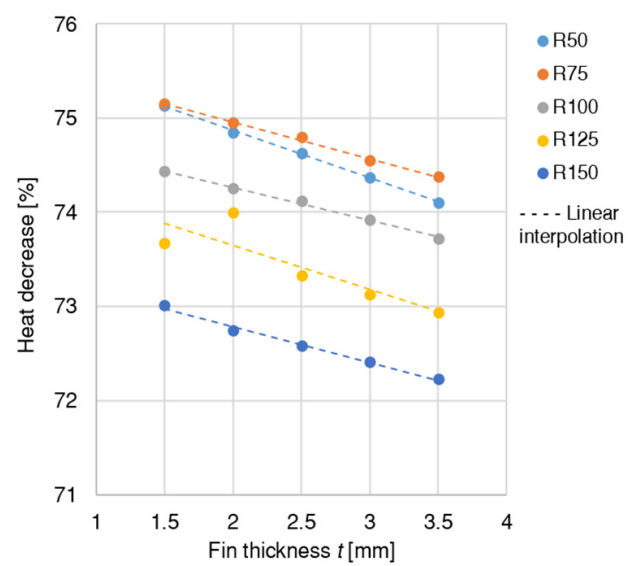

(b)

Figure 18. (a) Heat transferred through the $1 \mathrm{~m}$ length of the finned tube with 16 fins, (b) Heat decrease due to frosting.

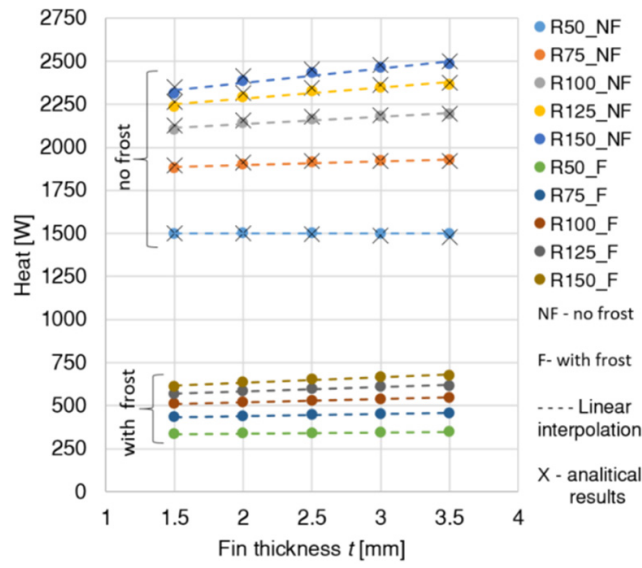

(a)

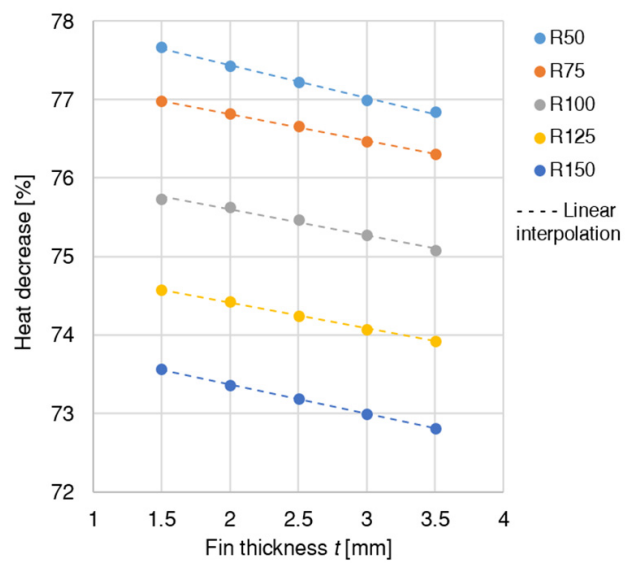

(b)

Figure 19. (a) Heat transferred through the $1 \mathrm{~m}$ length of the finned tube with 20 fins, (b) Heat decrease due to frosting. 
For finned tubes without frosting, the temperature at the perimeter of the central tube was about the same as the temperature of the medium, which was $-160{ }^{\circ} \mathrm{C}$. For fins distributed around the central pipe, the temperature increased radially. For example, for the tube with 8 fins and dimensions $R=100 \mathrm{~mm}$ and $t=2.5 \mathrm{~mm}$ (Figure 10), the temperature increased radially from $-160{ }^{\circ} \mathrm{C}$ at the central tube to $-122{ }^{\circ} \mathrm{C}$ at the tip of the fin surrounded by ambient air with a temperature of $20^{\circ} \mathrm{C}$. Analogous temperature distribution patterns were obtained for all other analyzed cases. As shown in Figures 8-12 and 13a), which refer to finned tube parameters $R=100 \mathrm{~mm}$ and $t=2.5 \mathrm{~mm}$, the number of fins had no significant impact on the radial temperature distribution. In the case of no frosting, the amount of heat delivered to the center pipe was affected by the number of fins, fin thickness and outer radius of the tube. It can be noticed that for a higher number of fins a much higher heat transfer through the tube surfaces with no frost was achieved. This was due to the increased heat transfer surface between the tube and environment.

For the tubes completely covered by frost, the temperatures on the outer surface of the frosted tubes were much higher than for the tubes without frosting. The higher the number of fins, the lower the temperature on the outer surface of the frosted tube. The higher number of fins increased the number of heat transfer paths from ambient air to the center pipe with the medium at low temperature.

For cases without frosting, the number and length of the fins had a crucial impact on the amount of heat transferred through longitudinal finned tubes. For example, for a finned tube with parameters: $n=4, R=100 \mathrm{~mm}, t=2.5 \mathrm{~mm}$, the amount of heat transferred through the finned tube without frosting was $Q 1=857 \mathrm{~W}$ (Figure 14a), while for a tube with parameters: $n=20, R=100 \mathrm{~mm}, t=2.5 \mathrm{~mm}$, the amount of heat was $Q 2=2165 \mathrm{~W}$ (Figure 19a), which was a two and a half times increase. On the other hand, for the case of total frosting, the values of heat supplied were $Q 1=309 \mathrm{~W}$ and $Q 2=531 \mathrm{~W}$, which indicated $64 \%$ and $74 \%$ decreases in heat transferred, respectively. The highest decreases of the heat transferred through longitudinal finned tubes caused by total frosting were obtained for the tubes with the highest number of fins.

\section{Conclusions}

During the regasification of LNG by means of ambient air vaporizers, the first rows of longitudinal finned tubes in the array containing natural gas in the liquid and gaseous phase are subjected to frosting during the vaporizers operation. This is a result of desublimation of humidity in the air at the outer surfaces of tubes which temperature is below zero. The phenomenon cannot be prevented by simple measures. Therefore, vaporizers usually work partially frosted and the frost melts during breaks in their operation. Part of the tubes in the array can also become completely frosted, which can significantly reduce heat transfer and therefore the efficiency of vaporizers. Therefore formation of frost has a disadvantageous effect on the vaporizer operation.

The obtained results of thermal analysis showed that for the case when fins are not covered by frost, the use of a higher number of fins within the tubes increases the heat transfer and therefore increases the efficiency of the ambient air vaporizer. The finned tubes in which the process of LNG evaporation takes place are totally or partially covered by frost. Those tubes do not require the high number of fins as they have a minor impact on the amount of delivered heat. The ambient air vaporizers with few tubes covered by frost may continue to operate, under the condition that the amount of frost does not affect the exceeding of the permissible mechanical loads acting on the vaporizer structure.

Author Contributions: Conceptualization, F.L. and E.L.; methodology, F.L. and E.L.; software, F.L. and E.L; validation, F.L., formal analysis, F.L. and E.L.; investigation, F.L. and E.L; writing-original draft preparation, F.L.; writing-review and editing, F.L.; visualization, F.L.; supervision, E.L.; project administration, F.L. All authors have read and agreed to the published version of the manuscript.

Funding: This research received no external funding.

Institutional Review Board Statement: Not applicable. 
Informed Consent Statement: Not applicable.

Conflicts of Interest: The authors declare no conflict of interest.

\section{References}

1. Lisowski, E.; Lisowski, F. Study on thermal insulation of liquefied natural gas cryogenic road tanker. Therm. Sci. 2019, 23 (Suppl. 4), S1381-S1391. [CrossRef]

2. Lisowski, F.; Lisowski, E. Design of internal supports for double-walled liquefied natural gas road tanker. Heat Transf. Eng. 2021, 1-10. [CrossRef]

3. Lee, K.S.; Kim, W.S.; Lee, T.H. A one-dimensional model for frost formation on a cold flat surface. Int. J. Heat Mass Transf. 1997, 40, 4359-4365. [CrossRef]

4. Jeong, H.M.; Chung, H.S.; Lee, S.C.; Kong, T.W.; Yi, C.S. Optimum design of vaporizer fin with liquefied natural gas by numerical analysis. J. Mech. Sci. Technol. 2006, 20, 545-553. [CrossRef]

5. Liu, S.; Jiao, W.; Ren, L.; Wang, H.; Zhang, P. Dynamic heat transfer analysis of liquefied natural gas ambient air vaporizer under frost conditions. Appl. Therm. Eng. 2017, 110, 999-1006. [CrossRef]

6. Wang, C.C.; Chang, Y.J.; Fan, S.J.; Sheu, W.J. Some observations of the frost formation in fin arrays. Heat Transf. Eng. 2004, 25, 35-47. [CrossRef]

7. Haldar, S.C. Laminar Free Convection around a Horizontal Cylinder with External Longitudinal Fins. Heat Transf. Eng. 2004, 25, 45-53. [CrossRef]

8. Wu, J.M.; Tao, W.Q. Numerical Computation of Laminar Natural Convection Heat Transfer around a Horizontal Compound Tube with External Longitudinal Fins. Heat Transf. Eng. 2007, 28, 93-102. [CrossRef]

9. Jeong, H.M.; Lee, Y.H.; Ji, M.K.; Bae, K.Y.; Chung, H.S. Natural convection heat transfer estimation from a longitudinally finned vertical pipe using CFD. J. Mech. Sci. Technol. 2009, 23, 1517-1527. [CrossRef]

10. Kopeć, P.; Niezgoda-Żelazko, B. Heat transfer on the outer Surface of vertical longitudinally finned tubes. In IOP Conference Series: Earth and Environmental Science; IOP Publishing: Bristol, UK, 2019; Volume 214, p. 012058. [CrossRef]

11. Kopeć, P.; Niezgoda-Żelazko, B. Optimisation of the Geometric Parameters of Longitudinally Finned Air Cooler Tubes Operating in Mixed Convection Conditions. Processes 2021, 9, 111. [CrossRef]

12. Sun, B.; Wadnerkar, D.; Utikar, R.P.; Tade, M.; Kavanagh, N.; Faka, S.; Evans, G.M.; Pareek, V.K. Modeling of Cryogenic Liquefied Natural Gas Ambient Air. Ind. Eng. Chem. Res. 2018, 57, 9281-9291. [CrossRef]

13. Gavelli, F. Computational fluid dynamics simulation of fog clouds due to ambient air vaporizers. J. Loss Prev. Process. Ind. 2010 23, 773-780. [CrossRef]

14. Vogler, W.E.; Halvorson, T.G. Atmospheric Vaporizer. U.S. Patent 4399660, 23 August 1983.

15. Grillo, F.J. Atmospheric Vaporizer Heat Exchanger. U.S. Patent 5174371, 29 December 1992.

16. Wieder, L.Z. Ambient Air Vaporizer Heater for Cryogenic Fluid. U.S. Patent 5251452, 12 October 1993.

17. Taler, J.; Duda, P. Solving Direct and Inverse Heat Conduction Problems; Springer: Berlin, Germany, 2006.

18. Chen, S.; Yao, S.; Xie, F. Analysis of thermal conductivity of frost on cryogenic finned-tube vaporizer using fractal method. Energy Power Eng. 2013, 5, 109-115. [CrossRef]

19. Ansys Academic Research Mechanical, Release 18, Engineering Data; ANSYS Inc.: Pittsburgh, PA, USA, 2018. 